\title{
- Original Articles
}

\section{Clinico-demographic profile of patients with acute and transient psychotic disorders}

\author{
S Ranjan ${ }^{1}$, R Shakya $^{2}$, PM Shyangwa $^{3}$ \\ Department of Psychiatry, ${ }^{1}$ National Medical College and Teaching Hospital, Birgunj, Nepal \\ ${ }^{2}$ Patan Hospital, Kathmandu, ${ }^{3}$ B.P. Koirala Institute of Health Sciences, Dharan, Nepal
}

\begin{abstract}
Background: There are only few studies on the clinico-demographic profile of acute and transient disorders, which is a common disorder in developing countries. Objective: To study the clinical presentation and socio-demographic profile of patients with Acute and transient psychotic disorders. Methods: Thirty patients diagnosed as Acute and transient psychotic disorders were assessed to record their socio-demographic profile, presence of stress, onset, presenting complains and the phenomenology using standard questionnaire. Results: ATPDs was more common in persons below thirty years of age (63.3\%), residing in rural areas (90\%), unemployed (76.7\%), low middle socioeconomic status (53.3\%), married $(63.3 \%)$, and member of nuclear family (63.3\%). Abrupt onset was seen in $73 \%$ of cases. Delusion of persecution was the most common psychopathology (86.7\%). All patients had impaired biorhythm and poor insight. Conclusions: Married unemployed persons below the age of thirty of low middle socioeconomic status residing in nuclear families in rural areas suffer from ATPDs more than others.
\end{abstract}

Keywords: acute and transient psychotic disorders, Nepal

\section{Introduction}

Acute and transient psychotic disorders (ATPDs) have been described since the end of the nineteenth century. Description has varied from one country to another. It was named as "acute primare Verruckheit" by German psychiatrists. In the French literature it was known by "Bouffee delirante". This psychosis has been described in almost all societies and countries. ${ }^{1}$

The tenth revision of the international classification of diseases and related health problems (ICD-10) has introduced a group termed as "acute and transient psychotic disorders" to include this group of psychoses. It is characterized by three typical features. ${ }^{2}$ They are: an acute onset presence of typical syndromes (a polymorphic syndrome and a

Address for correspondence

Dr Sanjeev Ranjan

Assistant professor, Department of Psychiatry

National Medical College and Teaching Hospital

Email: drsanjeevranjan@yahoo.com typical schizophrenic syndrome); and the presence of associated acute stress.

Only a few studies have been carried out on the clinico-demographic profile. In our country study on this topic, is lacking to our best knowledge. So this study was undertaken to study the clinicodemographic profile of patients with ATPDs.

The study was carried out to assess the sociodemographic profile of patients with Acute and transient psychotic disorders.

It was also aimed to understand the clinical presentation (phenomenology) in patients with Acute and transient psychotic disorders.

\section{Methods}

Thirty patients presenting to the psychiatry department of B.P.Koirala Institute of Health Science (both inpatients and outpatients) and diagnosed as ATPDs were included in the study. A semi-structured self designed questionnaire was applied to the patient 
and his relatives to collect and record the data on the socio-demographic variables, stresses and associated physical illness, duration of illness, signification past or family history, mental status examination and the psychiatric diagnosis.

Patients earning up to 32,000 rupees per annum were included in low socioeconomic group; between 32,001-64,000 rupees in low middle; 64,000-99,200 rupees in middle and 99,200 rupees and above in high socio-economic group. ${ }^{3}$

"Social support" in this study includes, financial, emotional, and companionship support from family members of the patient.

The onset of the illness was classified into abrupt or acute as per the research diagnostic criteria of ICD10 (1992). Abrupt onset is defined as "a change from a state without psychotic features to a clearly abnormal psychotic state, within a period of fortyeight hours or less and acute onset for more than 48 hours but less than two weeks".

ICD-10 sections on acute and transient psychotic disorders defines acute stress as "events that would be regarded as stressful to most people in similar circumstances, within the culture of the person concerned". ICD-10 mentions "bereavement, unexpected loss of partner or job, marriage, or the psychological trauma of combat, terrorism and torture" as typical examples of acute stress. ${ }^{2}$

Precipitating factors includes events that occurred at the start of this illness and led to its development. The study was conducted from January 2005 - June 2006. Patients aged between 15 to 60 years who fulfilled the diagnostic criteria of Acute and transient psychotic disorders according to ICD 10-DCR were included in this study. Only the patients whose relatives or caretaker had given written consent to participate in this study were included.

Patients having gross organic brain disorders, obvious drugs or alcohol intoxication, mental retardation, history of previous episode of psychotic illness and the patients who have been on antipsychotic treatment immediately prior to our contact were excluded from the study.

\section{Results}

\section{Socio-demographic profile}

The maximum number of patients with acute and transient psychotic disorders (ATPDs) was in the age group 25-34 years (43.3\%). The mean age was
26.7 years $(\mathrm{SD} \pm 8.53)$. Majority $(63.33 \%)$ of patients were below thirty years of age. Only one patient was in 45 and above age group. Out of 30 patients $15(50 \%)$ were male and rest were females. Of the 30 patients with ATPDs, $33.3 \%$ were housewives; $23.3 \%$ were farmers; $20 \%$ were students and 6-10\% each comprised of laborers, shopkeepers \& others.

Great majority of the patients $(96.7 \%)$ followed Hindu religion.

Majority of the patients (90\%) resided in rural areas. Larger proportion of patients were educated up to secondary level (33.3\%), about $20 \%$ of the patients were educated up to lower secondary level, $16.7 \%$ were illiterate and $10 \%$ had passed higher secondary. Graduates, literates and educated up-to primary level, each comprised of about 6 to $7 \%$ of the patients. Majority of the patients were unemployed (76.7\%). More than half $(53.3 \%)$ of the patients belonged to low middle socio-economic group. $30 \%$ belonged to middle socio-economic group while $13.3 \%$ belonged to low socio-economic group and only $3.3 \%$ belonged to the high economic group.

Most of the patients were married (63.3\%), 33.3\% were single and $3.3 \%$ separated. Most of the patients belonged to nuclear family (63.3\%).

\section{Clinical Profile of subjects with ATPDs}

Acute stress was present in $60 \%$ of the cases of ATPDs. Abrupt onset was seen in $73.3 \%$ of the patients and acute onset in $26.7 \%$ patients with ATPDs.

Precipitating factor was present in $10 \%$ of patients.

Table 1: Clinical profile of subjects with ATPDs

\begin{tabular}{|c|c|c|}
\hline Rapidity of onset & Frequency $(\mathrm{n})$ & Percent $(\%)$ \\
\hline Abrupt & 22 & 73.3 \\
\hline Acute & 8 & 26.7 \\
\hline \multicolumn{3}{|l|}{ Acute Stress } \\
\hline Present & 18 & 60.0 \\
\hline Absent & 12 & 40.0 \\
\hline \multicolumn{3}{|l|}{ Precipitating Factor } \\
\hline Present & 3 & 10.0 \\
\hline Absent & 27 & 90.0 \\
\hline Total no. of patient & 30 & 100.0 \\
\hline
\end{tabular}

All patients had continuous course of illness. Social support was adequate in all cases (100\%). 
Medical illness was present in 3 cases (10\%). Preceding history of fever was present in 1 case (3.3\%). Substance use was present in $10 \%$ of the patients. Cannabis use was present in $6.7 \%$ while nicotine use in $3.3 \%$ of patients.

The maximum number of patients presented with illness of 5-9 days duration. The mean duration of illness at the time of presentation was 8.8 days.

Table 2: Duration of illness at the time of presentation

\begin{tabular}{|l|l|l|}
\hline Duration & Frequency $(\mathrm{n})$ & Percent $(\%)$ \\
\hline 1-4 days & 7 & 23.3 \\
\hline 5-9 days & 11 & 36.7 \\
\hline 10-14 days & 7 & 23.3 \\
\hline 15-19 days & 3 & 10.0 \\
\hline 20-24 days & 1 & 3.3 \\
\hline 30 and above & 1 & 3.3 \\
\hline Total no. of patient & 30 & 100.0 \\
\hline
\end{tabular}

Duration of hospital stay was between 1-7 days in $30 \%$ of the patients and 8-14 days in another $30 \%$ of the patients. The mean duration of hospital stay was 15 days.

Table 3: Duration of hospitalization

\begin{tabular}{|l|c|c|}
\hline Duration (in days) & Frequency (n) & Percent (\%) \\
\hline $1-7$ & 9 & 30.0 \\
\hline $8-14$ & 9 & 30.0 \\
\hline $15-21$ & 6 & 20.0 \\
\hline $22-28$ & 1 & 3.3 \\
\hline $29-35$ & 2 & 6.7 \\
\hline $36-42$ & 2 & 6.7 \\
\hline 43 and above & 1 & 3.3 \\
\hline Total no. of patient & 30 & 100.0 \\
\hline
\end{tabular}

Delusion of persecution was present in majority of patients $(86.7 \%$ ) and delusion of grandiosity in $26.7 \%$ of the cases. About $36.7 \%$ subjects had polymorphic picture. Disorganized behavior was present in $23.3 \%$ of the patients. Details of the psychopathology have been provided in the Table 4. None of the subjects met the criteria for intoxication or dependence to any substance. No temporal relationship between the substance use and onset of this illness was found .
Table 4: Psychopathology

\begin{tabular}{|l|c|c|}
\hline Psychopathology & $\begin{array}{c}\text { Frequency } \\
\text { (n) Present }\end{array}$ & $\begin{array}{c}\text { Percent } \\
(\%)\end{array}$ \\
\hline Delusion of persecution & 26 & 86.7 \\
\hline Delusion of grandiosity & 8 & 26.7 \\
\hline Polymorphic picture & 11 & 36.7 \\
\hline Disorganized behaviour & 7 & 23.3 \\
\hline $\begin{array}{l}\text { First rank symptoms of } \\
\text { schizophrenia }\end{array}$ & 8 & 26.7 \\
\hline Hallucinatory behaviour & 9 & 30.0 \\
\hline Catatonia & 3 & 10.0 \\
\hline Total no. of patient & 30 & 100.0 \\
\hline
\end{tabular}

Another feature of psychosis, "lack of insight" was present in all cases. Similarly biorhythm was impaired in all the cases.

All patients with ATPDs had adequate social support. The onset of ATPDs was abrupt in most of the patients. In most of the patients with ATPDs stressor was present. Delusion of persecution was the most common psychopathology. All patients had impaired biorhythm and insight was absent in all of them.

\section{Discussion}

In our study, usual age group of patients with Acute and transient psychotic disorders (ATPDs) were similar to studies done by Sajith et al and ICMR., 1 The mean age of our patients was 26.7 years.

Majority of the studies have shown ATPDs to be more common in females as compared to males. ${ }^{4-7}$ Study by Singh et $\mathrm{al}^{8}$ in Nottingham however; found ATPDs to be more common in men than in women (1.87:1). In our study, there was equal proportion of male and female patients (1:1) as found in the study done in 4 centers in India. ${ }^{1}$ There could be many explanations for this observation. Firstly, in developing countries like Nepal and India, were society is male dominant, males are more socially valued than female. Generally males are the main earning members of the family. If they get ill, they are brought to treatment immediately. Females are generally neglected. So, the female predominance in ATPD might not have been seen in our study. Secondly, the sample size was small.

With regard to occupation, $33.3 \%$ of our patients were housewives, $23.3 \%$ were farmers, and $20 \%$ were students. Similar study done in developing country India showed that acute psychosis was more common in cultivators and laborers at 2 centers and 
in household workers at one centre. ${ }^{1}$ In the current study only small number of cases $(6.7 \%)$ belonged to laborer occupation. Most of our patients (96.7\%) were Hindus. This is because the majority of population of Nepal (80.6\%) follows Hindu religion. ${ }^{9}$ The vast majority of subjects $(90 \%)$ were from rural area. This supports the finding from other study on acute psychosis. ${ }^{10}$ Majority of the population in Nepal reside in rural setting, which might also be reflected in this study.

Nearly $33.3 \%$ of our patients were educated up to secondary level. About $20 \%$ were educated up to lower secondary level and $16.7 \%$ was illiterate. Other studies have also shown similar mixed results. They have shown acute psychoses to be more common in patients educated up to high school and above at some centre; and in subjects with no education at other centers. ${ }^{1}$ This could be the mere reflection of low education status in the general population. Majority of our patients were unemployed (76.7\%). More than half $(53.3 \%)$ belonged to low middle socioeconomic status. Other study also supports this finding and has reported that acute psychoses are more common in families of lower socio-economic status.

Subjects with acute and transient psychotic disorders in our study were mostly married $(63.3 \%)$, only $33.3 \%$ were single. Other study conducted in developing country setting also show similar result with $53 \%$ of patients were married and $48 \%$ were single. ${ }^{1}$ All patients in our study had adequate social support. This can be explained as in other psychiatric illness like schizophrenia where social support is good in developing countries. It has been hypothesized that developing countries are more socio-centric, with an emphasis on social relations and a range of rules, roles and conventions, more so in village setting, where people still stick to conventional norms. ${ }^{11}$ Also, people of same community, generally, stay in one locality making social support stronger and cohesive. The 'onset' of Acute and transient psychotic disorders was abrupt in most of patients (73\%), similar to one reported by ICMR and Sajith et al. ${ }^{1,4}$ Presence of stress is one of the specifier of the ICD-10 diagnosis of ATPDs. In our study $60 \%$ of the patients had the history of presence of stressor (mental stressor). This supports the ICD-10 use of 'associated acute stressor' as a specifier. Associations between stressors and ATPDs are reported elsewhere as well., ${ }^{1,7}$
In this study the numbers of cannabis users $(6.7 \%)$ are more than nicotine users $(3.3 \%)$ although the number of nicotine users is found to be more than the former in Nepal.

Studies have shown association between antecedent fever and acute psychosis in developing country ranging from eighteen percent ${ }^{1}$ to forty seven percent ${ }^{11}$, considering fever as a biological correlate of acute and transient psychosis. In our study, only one patient out of $30(3.3 \%)$ had preceding history of fever.

Regarding the phenomenology, our study showed presence of "delusion of persecution" to be the most common psychopathology, similar to previous studies. ${ }^{1,4}$

As in our study, impaired biorhythm (reduced sleep and reduced appetite) was present in the majority of the patients $(>95 \%)$ with acute polymorphic psychotic disorders in Sajith et al study. ${ }^{4}$

Limitation of the study: The conclusions drawn are from only thirty patients.

\section{Conclusion}

Acute and transient psychotic disorders were more common among individuals below age of thirty. It was equally prevalent among male and females and was found mostly in individuals from rural settings. It was more common in unemployed married persons belonging to low middle socio-economic status.

Acknowledgement: We are thankful to B. P. Koirala Institute of Health Sciences for allowing us to conduct the research.

\section{References}

1. Collaborative Study on the Phenomenology and Natural History of acute Psychosis. Indian Council of Medical Research. New Delhi, 1989: 2-31.

2. World Health Organization. The ICD-10 Classification of Mental and Behavioral Disorders. Clinical description and diagnostic guidelines 2002: 99-104.

3. Park K. Park's textbook of preventive and social medicine. Fifteenth Edition. Social Sciences and Medicine; 1997.

4. Sajith GS, Chandrasekaran R, Unni SEK and Sahai A. Acute Polymorphic psychotic disorder: diagnostic stability over 3 years. Acta 
Psychiatrica Scandinavica 2002; 105(2), page 104 - February 2002, doi: 10.1034/j. 16000447.2002.01080.x.

5. Mojtabai R, Susser SE, and Bromet JE. Clinical Characteristics, 4-Year Course, and DSM-IV Classification of Patients with Non affective Acute Remitting Psychosis. American Journal of Psychiatry 2003; 160:2108-2115.

6. Pillmann F and Marneros A. Longitudinal followup in acute and transient psychotic disorders and schizophrenia. British Journal of Psychiatry 2005; 187:286-7.

7. Alaghband-Rad J, Boroumand M, Amini H, Sharifi V,Omid A, Davari Ashtiani, et al. Nonaffective Acute Remitting Psychosis: a preliminary report from Iran. Acta Psychiatrica Scandinavica2006; 113 (2): 96 February 2006 doi:10.1111/j.1600-0447.2005.00658.x.
8. Sing SP, Burns T, Amin S, Jones PB, Harrison G. Acute and transient Psychotic disorders: precursors, epidemiology, course and outcome. British journal of psychiatry 2004; 185:452-459.

9. Population census 2001, National report. HMG Nepal. Published by Central Bureau of Statistics, in collaboration with UNFPA Nepal, June 2002.

10. Susser, E. and Wanderling, J. Epidemiology of non-affective acute remitting psychosis. Archives of General Psychiatry, 1994; 51:294-301.

11. Mojtabai R. Acute and Transient Psychotic Disorders and Brief Psychotic Disorder. Sadock JB, and Sadock AV Editor. Comprehensive Textbook of Psychiatry. $8^{\text {th }}$ Edition. 2005; 1: 15121522. 